Counterparty Risk, Impact on Collateral

Flows, and Role for Central

\title{
Counterparties
}

Manmohan Singh and James Aitken 


\title{
IMF Working Paper
}

Monetary and Capital Markets Department

\section{Counterparty Risk, Impact on Collateral Flows and Role for Central Counterparties}

\section{Prepared by Manmohan Singh and James Aitken ${ }^{1}$}

Authorized for distribution by Inci Ötker-Robe

August 2009

\begin{abstract}
This Working Paper should not be reported as representing the views of the IMF.

The views expressed in this Working Paper are those of the author(s) and do not necessarily represent those of the IMF or IMF policy. Working Papers describe research in progress by the author(s) and are published to elicit comments and to further debate.
\end{abstract}

Counterparty risk in the United States stemming from exposures to OTC derivatives payables (after netting) is now concentrated in five banks-Goldman Sachs, JPMorgan, Bank of America, Morgan Stanley and Citi. This note analyzes how such risks have shifted over the past year. We estimate that the adverse impact of counterparty risk on high-grade collateral flows and global liquidity due to decrease in rehypothecation, reduced securities lending, and hoarding of cash by major banks is at least $\$ 5$ trillion. In order to mitigate counterparty risk, there have been regulatory initiatives to establish central counterparties (CCPs). From a policy perspective, counterparty risk remains large at present and recent experience has shown that OTC derivative positions are not supported by sufficient capital, constituting a major risk for participants in this market.

JEL Classification Numbers:F37; G11; G15; G28

Keywords: Counterparty Risk, Large Complex Financial Institutions, OTC derivatives, Collateral Flow, Central Counterparties

Author’s E-Mail Address: msingh@imf.org; ja@aitkenadvisors.com

\footnotetext{
${ }^{1}$ Manmohan Singh is a Senior Economist with the IMF and James Aitken is with Aitken Advisors LLP. The authors wish to thank Darrell Duffie, Daniel Heller, Paul Mills, Inci Otker-Robe, Peter Stella, Kimberly Summe, Christopher Tsuboi, Christian Upper, Kurt Wilhem, Alexander Yavorsky, and participants at the CCP12 conference in Budapest for their helpful comments. The views expressed are those of the authors and do not reflect those of the IMF or Aitken Advisors. The authors are responsible for any errors.
} 


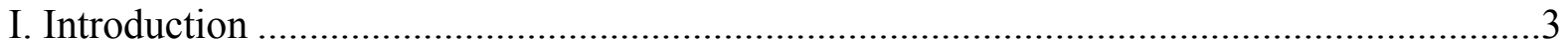

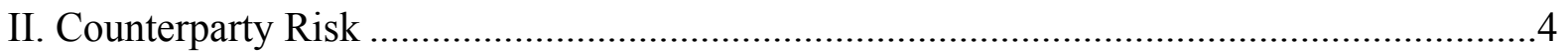

III. The Changing Profile of Counterparty Risk in the United States..................................6

IV. The Adverse Impact of Counterparty Risk on Global Liquidity ..................................

V. Regulatory Thrust for a Central Counterparty .......................................................... 10

VI. Conclusions and Policy Implications.............................................................. 12

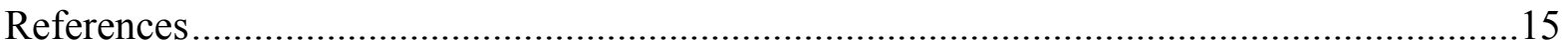

Tables

1. Snapshot of Reduced Collateral Posting Among LCFIs................................................8

2. Securities Lending by Major Custodians .......................................................................

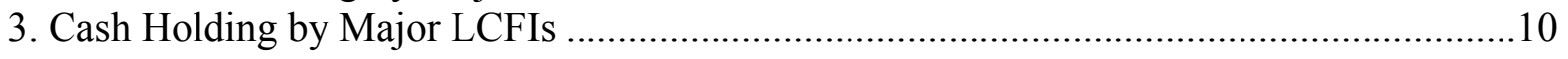

Figures

1. Illustrative Repricing of Derivatives When a Large Financial Institution Fails ..................5

2. Counterparty Liabilities of Major U.S. Banks ............................................................ 7

Appendixes

1. Methodological Issues in Computing Connectedness in Counterparty Risk 


\section{INTRODUCTION}

The over-the-counter (OTC) derivatives market has grown considerably in the past two years. Notional amounts of all categories of the OTC contracts reached almost $\$ 600$ trillion at the end of December 2008. These include foreign exchange (FX) contracts, interest rate contracts, equity linked contracts, commodity contracts, and credit default swaps (CDS) contracts. Interest rate contracts continue to be the largest segment of this market, comprising 70 percent of all OTC derivatives market contracts or about $\$ 420$ trillion.

There has been very little (if any) research that looks at the full gamut of the OTC derivatives market. Most of the recent discussion has been limited to credit derivatives (or the CDS market), which represents less than 10 percent of the overall notional OTC derivatives market, as per Bank for International Settlements (BIS) data. ${ }^{2}$ One of the most cited recent works is by Barclays Bank where they acknowledge that "counterparty risk is theoretically present in all asset classes: FX derivatives, interest rate swaps, equity derivatives, commodity derivatives, and credit derivatives." 3 Also, a recent IMF paper (Segoviano and Singh, 2008), looked at all OTC derivatives, but the data and methodology were focused on the situation around the time of Bear Stearn's demise. Post Bear Stearns and especially after Lehman collapse, much has changed. ${ }^{4}$

In this paper, we provide a different perspective to measure counterparty risk, compared to other sources (e.g., Office of Comptroller of Currency's Quarterly Report on Bank and Derivatives Activities, or BIS bi-annual technical report on OTC Derivatives Market Activity). We explain that neither the notional value of OTC contracts nor the gross market value of these contracts (essentially the total value of all the derivatives that are in-themoney) provide a basis to measure counterparty risk. Instead, we discuss the importance of "netting" within and across all categories of OTC derivative contracts and of reducing this netted amount by the "assigned" cash collateral to come up with a relevant measure for exposure to counterparty risk.

The aversion to deal with large complex financial institutions (LCFIs) due to their counterparty risk has implications for global liquidity. Overall, high grade collateral flows have fallen significantly both as LCFI clients have reduced the free flow of collateral to LCFIs, and LCFIs themselves have locked up collateral on their balance sheets.

In order to mitigate counterparty risk, there have been regulatory initiatives to establish central counterparties (CCPs). In theory, CCPs may reduce counterparty risk by multilateral

\footnotetext{
${ }^{2}$ A comprehensive breakdown of the OTC derivative market is available in Table 1 of the Bank for International Settlements' release, "OTC derivatives market activity in the second half of 2008," May 2009.

${ }^{3}$ Barclays Quantitative Credit Strategy Research Note: Counterparty risk in credit markets, February 20, 2008.

${ }^{4}$ See Appendix 1 and forthcoming IMF Working Paper (Singh and Youssef, 2009) that discusses methodological issues to consider when quantifying counterparty risk, since the collapse of Lehman.
} 
netting of derivative trades when a large financial fails and back-stop the systemic risk stemming from the OTC derivatives market.

The paper is organized as follows. The introductory section provides an overview of counterparty risk, the central theme of the paper. Section II defines counterparty risk when a large institution fails. Section III focuses on the changing profile of counterparty risk and highlights five U.S. banks where this risk is concentrated-Goldman Sachs, JPMorgan, Bank of America, Morgan Stanley and Citi. Section IV estimates the adverse impact of counterparty risk on high-grade collateral flows due to decrease in rehypothecation, reduced securities lending, and hoarding of cash by major banks to be at least $\$ 5$ trillion. Section V of the paper discusses the role for CCPs, and Section VI concludes with a policy suggestion that unless OTC derivative positions are supported by sufficient capital, counterparty risk will remain large.

\section{COUnTERParty Risk}

Counterparty risk largely stems from the creditworthiness of an institution. In the context of a financial system that includes banks, broker dealers, and other nonbanking institutions (e.g., insurers and pension funds), counterparty risk will be the aggregate loss to the financial system from a counterparty that fails to deliver on its OTC derivative obligation. ${ }^{5}$

In order to highlight the importance of counterparty liabilities, it is necessary to discuss notional amounts of outstanding OTC contracts and the gross market value of OTC contracts. Notional amounts are defined as the nominal value of all OTC derivative deals concluded on the reporting date. These amounts provide a measure of the size of the market, but do not provide a measure of risk. Risk arising from open derivatives stems from several factors including price changes, volatility, leverage and hedge ratios, duration, liquidity, and counterparty risk.

Gross market values are derived from the replacement cost of open contracts that are in a current position at current market prices and thus, in the event of a counterparty default, would roughly represent defaulted claims on counterparties. Although gross market values provide a rough aggregate measure of counterparty risk, these values do not account for netting and therefore overstate the risk from open contracts.

We define the exposure of the financial system to the failure of a particular counterparty as the liabilities of a counterparty to all others in the financial system. These liabilities stem from the counterparty's OTC derivatives payables after netting under a master netting agreement such as ISDA, or a cross-margining agreement, which have been further reduced by assigning cash or equivalent collateral.

\footnotetext{
${ }^{5}$ We understand that cross-margining/netting will be specific to the International Swaps and Derivatives Association (ISDA) master agreement of the institution; thus, it is possible that OTC derivatives may not be offset against repo positions. Furthermore, in the United States, only "core" affiliates are entitled to "mutuality" under one master agreement. Thus, peripheral affiliates will not be covered.
} 
The financial market turmoil of recent months has highlighted the importance of counterparty risk. Recent data show that counterparty risk within U.S. banks, post-Lehman, is now concentrated in five institutions relative to the period before Bear Stearns. Recent data from the Office of the Comptroller of the Currency (OCC) and 10Q reports highlight five U.S. banks (JPMorgan, Citi, Bank of America, Goldman Sachs and Morgan Stanley) that are the major players in the derivatives market. ${ }^{6}$ From a systemic risk perspective, counterparty risk is the risk to others in the global system if a large financial institution goes under (i.e., bankruptcy or some other form of organized resolution), which would mean that the tradereplacement price for the residual derivatives payable obligations (i.e., the unsecured receivables for those who have lost their counterparty) will need to be agreed upon immediately. The cost of putting on the exact same trade can be very high (see Figure 1).

Figure 1. Illustrative Repricing of Derivatives When a Large Financial Institution Fails

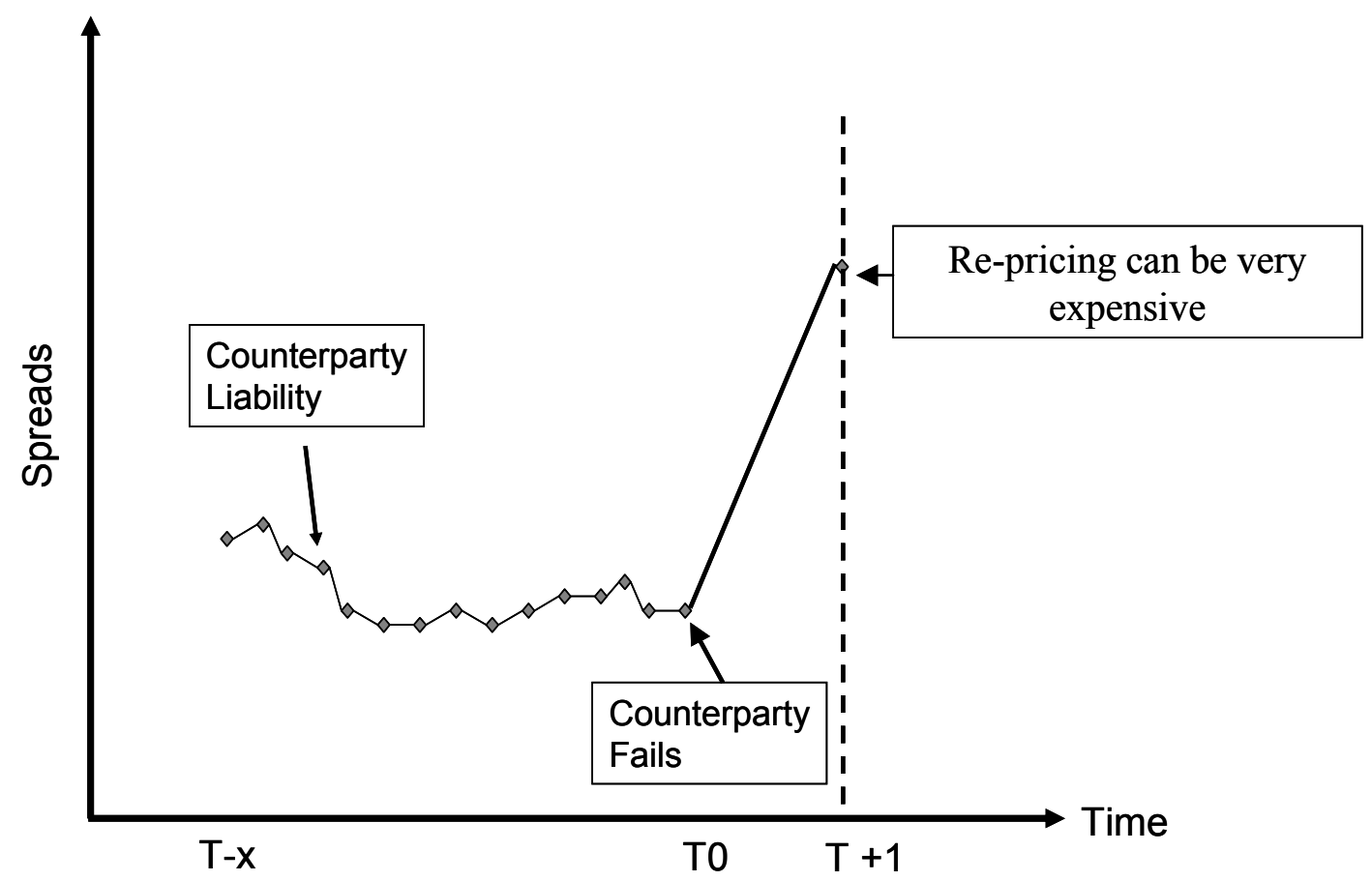

Lehman's bankruptcy illustrates the asymmetry between the treatment of derivatives payables and derivatives receivables. Moody's (2008) mentions that when Lehman's default was being considered at the weekend session (September 13-14) at NY Fed, only a limited amount of outstanding derivatives payable trades were re-priced as participants expected significant price changes and operational difficulty in replacing a sizeable volume of trades. S\&P (2009) emphasizes that before Lehman's default, in-the-money contracts in favor of

\footnotetext{
${ }^{6}$ OCC's Quarterly Report on Bank Trading and Derivatives Activities, Fourth Quarter, 2008 includes HSBC (and not Morgan Stanley) in the top five institutions where large derivative activity is concentrated. Morgan Stanley by year end-2008 had not put its derivatives activities under its nationally chartered bank as Goldman had done (at least with its interest rate swap positions).
} 
Lehman (derivatives receivables) may not have materialized because clients could elect not to call an early termination of a CDS contract if the mark-to-market value of the CDS was not in their favor. Therefore, terminating the contract would entail a payout to Lehman (or its bankruptcy trust). This asymmetry of legal treatment between derivatives payables and receivables is very important when a firm is near bankruptcy-clients terminate contracts in their favor but not those where Lehman was in favor.

\section{The Changing Profile of Counterparty Risk in the United States}

The global OTC derivatives market is very concentrated with about ten bank dealers responsible for about 90 percent of trading volume (Fitch 2007). ${ }^{7}$ It is useful to note that the counterparty liabilities of Lehman (as per their last 10Q filing on July 10, 2008) was about $\$ 24$ billion. $^{8}$ This is a useful gauge when comparing counterparty liability exposure of the five key U.S. banks and how they have evolved over the past year.

The counterparty liability exposures of the five major banks changed over the course of the crisis:

- Citibank's counterparty liability exposure decreased significantly to $\$ 81$ billion as of end-March 2009, relative to $\$ 126$ billion as of March 2008, largely due to continuing concerns on having Citi as a counterparty (see Figure 2).

- Goldman Sachs' counterparty risk to the financial system is the largest, at \$91 billion as of end-March 2009, relative to around \$100 billion as of March 2008; the change is noteworthy since others have gained or stabilized their market share only due to mergers. In other words, Citi and Goldman symbolize two extremes: Citi has been viewed as an unreliable counterparty (with its CDS spreads going over $600 \mathrm{bps}$ prior to the stress test results), while Goldman has relatively strengthened its position since it registered to be a 'bank,' and one of the first to repay TARP funds.

- JPMorgan's exposure to OTC derivatives payables was about $\$ 86$ billion at endMarch 2009, compared to $\$ 68$ billion as of March 2008. This was partially due to the absorption of Bear Stearns and WAMU, but markets also suggest the 'too-close-toFed' factor as being crucial for JPMorgan gaining business (see Singh and Aitken, 2009).

\footnotetext{
${ }^{7}$ Hedge funds mostly transact through their prime-brokers. The BIS survey on OTC derivatives would pick such transactions as bank-dealer trades.

${ }^{8}$ Some may argue that gross in-the-money negative exposure may be a more relevant measure of counterparty liabilities. We understand from legal sources that the after-netting and after the assigned cash collateral figures were more relevant during the weekend session at Lehman; typically, these figures are after taking into consideration hedge replacement risk and thus a better proxy than gross liabilities. As a rule of thumb, after netting liabilities are roughly 5 percent of gross liabilities (as per BIS data). After netting liabilities are approx 20-25 basis points of the notional liabilities as per IMF staff estimates (Segoviano and Singh, 2008).
} 
- $\quad$ Bank of America/ Merrill Lynch appears to have almost tripled its counterparty risk exposure to $\$ 77$ billion as of end-March 2009, relative to March 2008, but this sizeable increase is due to the merger with Merrill Lynch; comparing figures below, BoA and Merrill Lynch had about $\$ 88$ billion in derivatives payable a year ago.

- Morgan Stanley's exposure has fallen slightly from $\$ 69$ billion as of end-March 2008 to $\$ 54$ billion as of end-March 2009. ${ }^{9}$

Figure 2. Counterparty Liabilities of Major U.S. Banks

(as of end-March 2009 and end-March 2008)

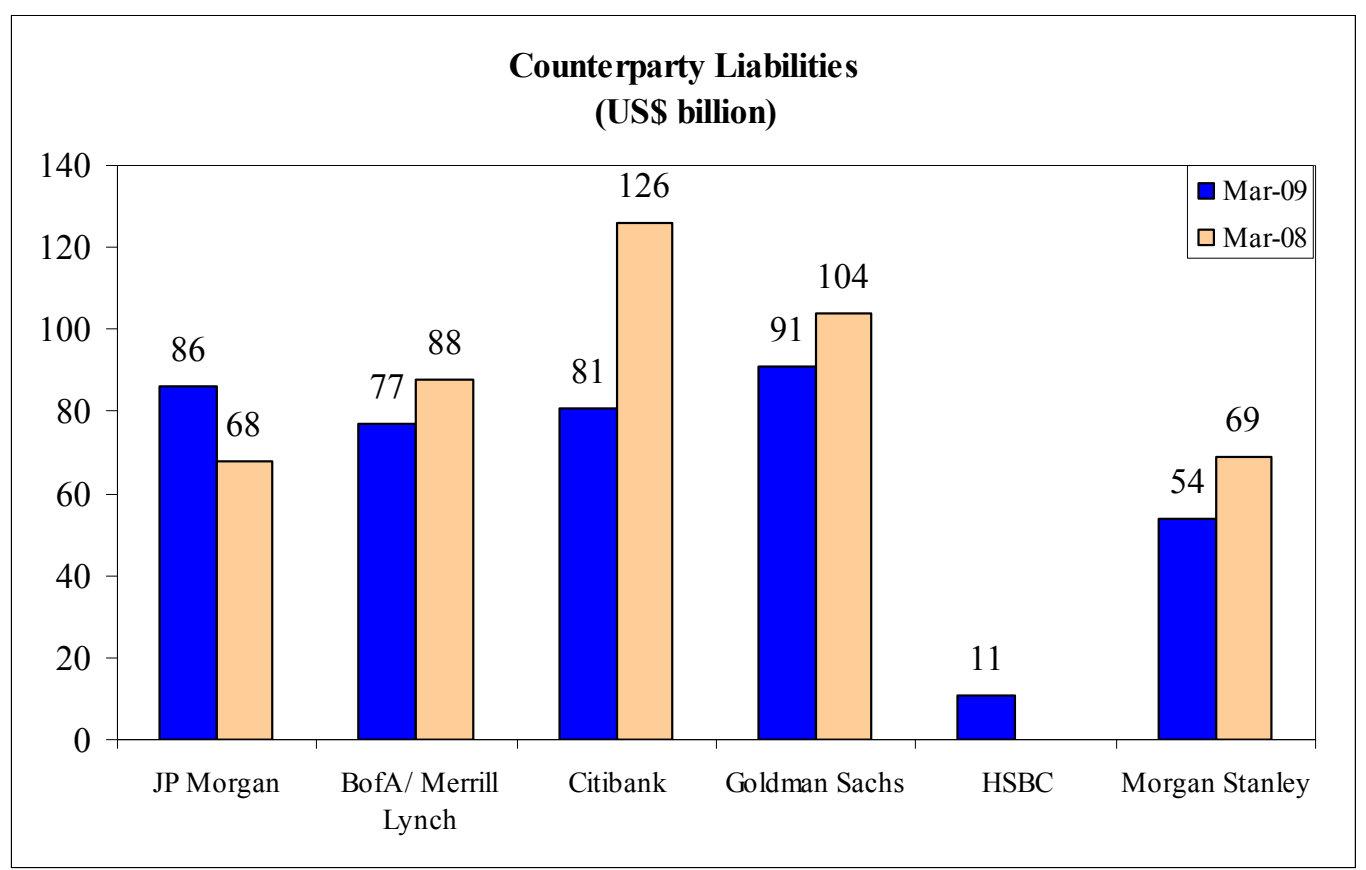

Source: $10 Q$ reports.

\section{ThE ADVERSE IMPACT OF COUNTERPARTy RISK ON GLOBAL LIQUIDITY}

The aversion to deal with some large complex financial institutions (LCFIs) due to their counterparty risk has implications for global liquidity. This is because collateral flows, within the financial system has fallen significantly and adversely impacted global liquidity (i.e., funding and trading liquidity). This largely stems from LCFI clients avoiding their high grade collateral to flow freely within the LCFIs, or LCFIs themselves locking up collateral in their balance sheets. This section shows anecdotal evidence of a sizeable drop in global liquidity

\footnotetext{
${ }^{9}$ HSBC is a U.K. bank primarily focusing on Asia; it remains intriguing that its not-so-large U.S. banking franchise supports a relatively large derivatives book in notional terms ( $\$ 3.7$ trillion) making it the fifth largest bank in terms of derivatives activity in the United States (source Office of Comptroller of Currency's, Quarterly on Derivatives, Fourth Quarter, 2008). However, the after-netting and after assigned cash collateral derivatives was about $\$ 11$ billion as of end-March 2009.
} 
from reduced rehypothecation, reduced securities lending and from sizeable hoarding of cash/cash equivalent by LCFIs. ${ }^{10}$

The fair value of securities received as collateral, which can be pledged (or rehypothecated) by major LCFIs, has fallen by about $\$ 2.5$ trillion since end-2007, (compare Nov 07 with Nov 08 in Table 1). ${ }^{11}$ Such collateral was mostly posted by clients of the LCFIs (especially hedge funds). Since the freezing of Lehman's assets in the United Kingdom, hedge funds have been opting not to rehypothecate their collateral and prefer segregated accounts or triparty custodian arrangements where they retain ownership of their margin that was posted as collateral (see Singh and Aitken, 2009). ${ }^{12}$

\section{Table 1. Snapshot of Reduced Collateral Posting Among LCFIs}

(In US\$ billions)

\begin{tabular}{lrrrrrrr}
\hline & Nov 05 & Nov 06 & Nov 07 & May 08 & Aug 08 & Nov 08 & Mar 09 \\
\hline LEH & 528 & 621 & 798 & 518 & & & \\
MS & 798 & 942 & 948 & 953 & 877 & 294 & 283 \\
GS & 629 & 746 & 891 & 869 & 832 & 579 & 610 \\
MER & 538 & 634 & 855 & 865 & 676 & 327 & \\
DEUT & & & 449 & & & 230 & \\
(Euros) & & & & & & 651 & \\
UBS & & & 1491 & & & & \\
(Euros) & & & & & & & \\
\hline
\end{tabular}

Source: $10 \mathrm{Q}$ and $10 \mathrm{~K}$ filings for U.S. firms; Annual reports for European firms.

Securities lending by custodians is also down sizeable. The number is at least $\$ 1$ trillion if we include other leading custodians such as Citigroup, HSBC etc. Table 2 shows the decline among the top three global custodians-Bank of New York, State Street and JPMorgan since end-2007.

\footnotetext{
${ }^{10}$ Rehypothecation is the practice that allows collateral posted by say a hedge fund to their prime broker, to be used again as collateral by that prime broker for its own funding. There are no limits to rehypothecation in the United Kingdom, (see Singh and Aitken, 2009).

${ }^{11}$ Admittedly, fair value of securities is determined by price times quantity, and we acknowledge that prices were declining (due to increased haircuts on many securities).

${ }^{12}$ As per footnote 9 of IMF Working paper by Singh and Aitken, 2009, JPMorgan increased its share of fair value of securities received as collateral. To this extent, the $\$ 2.5$ trillion figure should be reduced to reflect the increased positions with JPMorgan.
} 
Table 2. Securities Lending by Major Custodians (In US\$ billions)

\begin{tabular}{lrrrr}
\hline & Dec. 31, 2007 & March 31, 2008 & June 30, 2008 & Dec. 31, 2008 \\
\hline Bank of NY & 619 & 637 & 567 & 341 \\
State Street & 558 & 591 & 550 & 325 \\
JP Morgan & 385 & 411 & 362 & 169 \\
Total & 1,562 & 1,639 & 1,479 & 825 \\
\hline
\end{tabular}

Source: $10 \mathrm{Q}$ and $10 \mathrm{~K}$ reports.

There is also evidence of a sizeable hoarding of cash or cash-equivalent by LCFIs. The typical reason provided by them is succinctly illustrated by Goldman Sachs's in its recent $10 \mathrm{Q}$, page 135:

"Our most important liquidity policy is to pre-fund what we estimate will be our likely cash needs during a liquidity crisis and hold such excess liquidity in the form of unencumbered, highly liquid securities that may be sold or pledged to provide same-day liquidity."

"The U.S. dollar-denominated excess is comprised of only unencumbered U.S. government securities, U.S. agency securities and highly liquid U.S. agency mortgage-backed securities, all of which are eligible as collateral in Federal Reserve open market operations, as well as overnight cash deposits. Our non-U.S. dollar-denominated excess is comprised of only unencumbered French, German, United Kingdom and Japanese government bonds and overnight cash deposits in highly liquid currencies."

Most large banks annual reports suggest that high-grade and liquid collateral is very much desired and kept on their books, although lower quality and less liquid collateral that is acceptable to the Fed and ECB has been deposited with them to raise cash via the various facilities offered by these central banks. ${ }^{13}$ Table 3 gives an illustration of the sizeable cash holdings. If the cash holdings with all the major LCFIs are counted, such cash holdings reach $\$ 1.5$ trillion. $^{14}$

\footnotetext{
${ }^{13}$ LCFIs have deposited AAA (and lower rated) collateral with NY Fed and ECB. However, AAA collateral varies between sub-prime/CDO products that are/were AAA, and unencumbered the U.S., French, German and the U.K. government bonds that are also AAA.

${ }^{14}$ The cash or cash-equivalent holding at end-2007 were not sizeable; hence changes between end-2007 and end-2008 are not shown.
} 


\section{Table 3. Cash Holding by Major LCFIs, end-2008 \\ (In billions of dollars)}

\begin{tabular}{ll}
\hline UBS & 200 \\
Bank of America & 170 \\
Goldman Sachs & 164 \\
Morgan Stanley & 145 \\
\hline
\end{tabular}

Source: $10 \mathrm{Q}$ and $10 \mathrm{~K}$ and similar filings.

In conclusion, several key points can be made. First, collateral flow (especially high-grade liquid collateral) within the financial system has fallen significantly and adversely impacted global liquidity. This is the risk capital and balance sheet capacity that may have otherwise been applied to proprietary trading, market-making and arbitrage activities that are integral to global liquidity. Second, since the velocity of collateral is greater than one, pledged collateral, repo markets and cash hoarding would have 'turned-over' more than once, if deployed effectively by the markets. Thus, the impact of the figures mentioned in Tables 1-3 on global liquidity (about $\$ 5$ trillion) is much greater than seems apparent from the figures alone and may have implications for monetary policy in some countries. We suggest that the counterparty risk associated with (some) LCFIs last year was a key reason why collateral was not put to full use. ${ }^{15}$ However, counterparty risk has not abated in the past year, and has perhaps concentrated further post-Lehman.

\section{Regulatory Thrust For a Central COUNTERPARTy}

There have been recent regulatory initiatives, especially in the United States, to establish a central counterparty clearinghouse. ${ }^{16}$ A clearinghouse or a central counterparty (CCP) interposes itself between the buyer and the seller and assumes the rights and obligations of both parties. In theory, a CCP may reduce systemic risk by applying multilateral netting of trades which not only reduces counterparty risk but also minimizes cash flows between counterparties. However, it is likely that most OTC derivatives will not end up on exchanges but will require central clearing. In this respect, the too-large-to-fail notion will continue to exist unless (i) some of the banks with large counterparty risk, as shown in Figure 2, also reduce their after-netting residual derivatives payables (as Citi has done over the past year), or (ii) CCPs act as the last buffer and inherit such counterparty risk. ${ }^{17}$

\footnotetext{
${ }^{15}$ Market sources, including discussions with large custodians, suggest that post Bear Stearns absorption by JPMorgan and especially after Lehman's bankruptcy, there was a 'run' for high grade collateral.

${ }^{16}$ The U.S. Treasury has also recently proposed legislation that would extend its ability to restructure LCFIs that may not fall under the scope of bank failure resolution mechanisms.

${ }^{17}$ Also, to augment Figure 2 of this paper, AIG has reduced its counterparty liabilities (as defined in this paper) from $\$ 30$ billion as of end-2008 to $\$ 5$ billion as of end-2009.
} 
Some issues need to be considered in the context of reducing counterparty risk and establishing a central counterparty clearinghouse:

- Will a CCP (or more than one), reduce systemic risk from LCFIs by transferring it to the $\mathbf{C C P}(\mathbf{s})$ ? It is increasingly likely that globally there will be more than one $\mathrm{CCP}$, although optimally, one global CCP that covers all OTC contracts would have the most efficient capital allocation (Duffie and Zhu, 2009). ${ }^{18}$

- Are there presently capacity at large banks for higher (initial) collateral posting, in light of the scarcity of collateral flow discussed above? Collateral requirements are likely to increase overall, despite cross-netting capabilities between CCPs. In general, dealers want more collateral today than prior to the crisis.

- What would constitute adequate capital for a CCP? Counterparty Liabilities, shown earlier in Figure 2, is a good starting point to estimate the size of capital that will be needed in determining the LCFIs and CCPs initial margin/collateral.

- Will there be interoperability (or linking of CCPs) and will the pooling of margin/collateral be symmetric? In other words, will all types of contracts be offloaded rather than one or two types that may be encouraged by the specialization and adequate capitalization of a CCP? Will CCPs specializing in interest-rate swaps where margin variation is continuous and not subject to jump risk, be willing to be linked (and back-stop) another CCP that specializes in CDS contracts only. ${ }^{19}$ Risks may increase if clearing is applicable to only certain types of OTC derivatives, as big dealers in OTC derivatives offset CDS and other OTC positions.

- Is a CCP a public good with associated implicit (national) guarantees, or will members underwrite all costs associated with a large member defaulting? There have been reports that some CCPs may consider asking for guarantees in (especially those clearing CDS contracts, where jump risk is large when a member fails). This stems from the desire to expand access to CCPs beyond banks (and to include hedge funds and other OTC derivative buyers). Segregating hedge funds margin money, in case a bank fails, gained prominence after Lehman's collapse (see Singh and Aitken, 2009).

- Will the existence of a CCP encourage more derivative activity? It is likely that systemic risk from derivatives will be spread from the present 6 to 10 LCFIs that dominate the OTC derivative market to about 10 to 15 entities (LCFIs plus CCPs).

\footnotetext{
${ }^{18}$ Bespoke contracts such as those originating between AIG FP credit derivatives may be difficult to move to a CCP (and unlikely to move to an exchange).

${ }^{19}$ Jump risk is associated with CDS contracts where the price of the underlying reference entity can move sizably during distress and especially around a credit event.
} 
This may increase derivative activity, provided netting is symmetric and augmented by sufficient capital allocation both at the LCFI and CCP levels, or via national/ jurisdictional implicit or explicit guarantees.

\section{Conclusions And Policy Implications}

Counterparty risk continues to loom large and has not abated over the past year since Bear Stearns absorption by JPMorgan. LCFIs with large counterparty liabilities that have been considered weak (e.g., Citi) relative to others (e.g., Goldman) have either lost derivative business to stronger derivative players or, have had to come up with sizeable cash or cash equivalent to reduce their derivatives payables position. Furthermore, global liquidity has suffered as a result of LCFI clients avoiding their high grade collateral to flow freely within the LCFIs or LCFIs themselves locking up collateral in their balance sheets.

Recent experience has shown that OTC derivative positions are not supported by sufficient capital, constituting a major risk for participants in this market. CCPs have been proposed recently as a way to reduce systemic risk by applying multilateral netting of trades. Although CCPs are a positive initiative, sufficient collateral and initial margin must back-stop derivative activity at both the LCFI and CCP level. Another key factor will be the interoperability of CCPs, which may entail collaboration (and implicit guarantees) at sovereign levels. Introduction of such a mechanism must be well thought out. In short, removing the "too-big-to-fail" notion genuinely requires additional capital from those LCFIs that are dominant in the OTC derivatives space. Otherwise, regulators risk the possibility that present tax payers bailouts in containing systemic risk to future implicit guarantees via CCPs. 


\section{Appendix 1. Methodological Issues in Computing Connectedness in Counterparty Risk}

There have been few attempts to define counterparty risk and the empirical work that has been undertaken has proved to be somewhat limited in scope. Credit Derivative Research (CDR) provides a counterparty risk index, which is an average of the CDS spreads of the largest 15 credit derivative counterparties, but it totally disregards other OTC derivatives or their notional, gross or after-netted derivative positions. The much cited Barclays Bank Quantitative Credit Strategy Note of February 20, 2008 also limited the scope of the analysis to credit derivatives only. Segoviano, and Singh, (2008), uses data until March 2008 and covers all OTC derivatives, but acknowledges the deficiencies of the methodology during extreme distress (i.e., post Bear Stearns). ${ }^{20}$

In summary, three issues have been identified and need to be incorporated into the various methodologies that estimate probabilities of interconnectedness within large financial institutions (or counterparty risk when analyzing counterparty risk stemming from their derivatives positions). ${ }^{21}$ First, we emphasize the difference in risk-neutral probabilities that are derived from CDS spreads and the market-adjusted probabilities that stem from empirical data such as Moody's KMV. Second, we highlight the recent divergence in the credit and equity markets as evidence from the recent crisis that has impacted large global banks. Lastly, the role of stochastic recovery is also considered when extracting default probabilities to estimate losses.

Price of Risk is the factor needed to convert risk-neutral probabilities (that are associated with CDS spreads) to real-world probabilities. The recent literature on this topic converges on the methodology of Amato (2005) that proxies the conversion factor by taking the credit signal or CDS spreads in the numerator, and an equity signal in the denominator (e.g., market adjusted EDF from Moody's KMV database). The BIS Quarterly Review, March 2009, shows that the price of risk in the recent crisis (2007/2008) has fluctuated from an average of about 4 to 12. Duffie et al (forthcoming) also shows large price of risk in the past couple of years relative to early periods. In other words, unlike the nondistress period, the risk-neutral probabilities derived via various methodologies using CDS spreads need to be adjusted by a nontrivial factor to determine real-world probabilities derived via EDF. ${ }^{22}$

\footnotetext{
${ }^{20}$ With reference to page 14 , second paragraph of the paper, the authors suggest that during distress, especially where bond prices jump, use of CDS data after Lehman will necessitate the use of variable recovery value or in its absence, the cheapest-to-deliver bonds.

${ }^{21}$ We refer to probability of default or distress in the broader context that includes conditional probabilities of default, joint probability of default, distance to distress, and joint default dependence (i.e., via the off-diagonal elements). In all such models, the general assumption has been to hold recovery value constant.

${ }^{22}$ So if a model finds probability of default for a bank at 0.9 via CDS spreads, and the associated price of risk for that bank is 10 , the probability of default that is relevant is 0.09 .
} 
Preliminary results of a forthcoming IMF working paper by Singh and Youssef also suggests that the price of risk for large global banks has been sizeable and varies between institutions. For example, around Lehman's bankruptcy in September 2008, the price of risk for many large banks was about 5 and in some cases for European banks it was higher than 10. Such large 'price of risk' may be useful to consider when comparing loss estimates using real world probabilities or risk-neutral probabilities. ${ }^{23}$

Divergence between credit and equity markets was significant in 2008 and this continues to be the case for LCFIs. Unlike nonfinancials, like GM or Chrysler, where bondholders have recently taken a haircut and losses via credit events associated with those holding their CDS contracts, LCFI bondholders have not suffered. This may follow from the too-big-to-fail criterion or the forbearance toward LCFI bondholders, both in the United States and Europe. The volatility in LCFI equity prices has therefore been large relative to that in their bond prices. $^{24}$ Thus, this divergence needs to be considered in probability models and augment the changing price of risk described above. The asymmetry in signals from both the credit and equity markets is especially important to consider in models using distance-to-distress where volatilities of debt and equity markets are key variables in determining the final output.

Furthermore, stochastic recovery is important to incorporate during distress as a credit default swap is mathematically a jointly stochastic function in probability and recovery value. During distress (i.e., when the underlying bond price is well below par) and jump risk is likely, the cheapest to deliver bond is a good proxy to stochastic/variable recovery (see Duffie, 1999 and Singh, 2004, and Singh and Spackman, 2009).

Figure 3. Citi and Goldman Cheapest-to-deliver Bonds

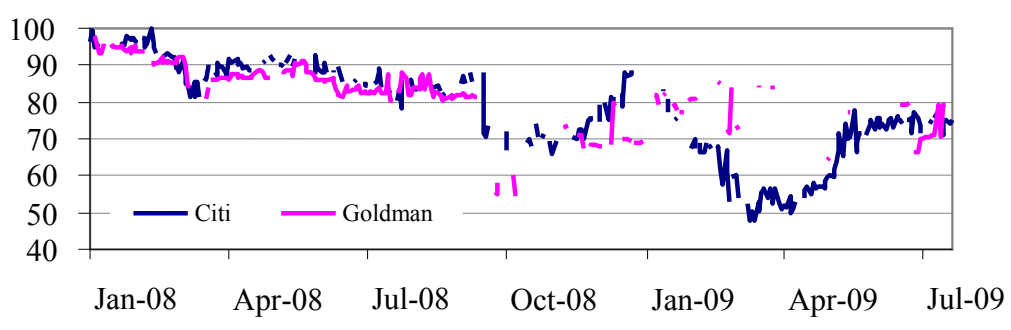

Source: Bloomberg

In conclusion, until we have a better idea of the magnitude of the biases and how best to correct the existing models, loss estimates for large banks from models should be interpreted cautiously.

\footnotetext{
${ }^{23}$ The price of risk uses 5 year cumulative EDFs. Moody's KMV uses the 5 year cumulative EDF when calculating 5 year EICDS (i.e., EDF implied 5 year CDS) which can be compared to actual 5 year CDS.

24 The OVCR (Equity Volatility and Credit Risk) function in Bloomberg allows comparison of actual CDS spreads to theoretical CDS equivalent spreads that are derived from equity prices, implied volatility and leverage.
} 


\section{REFERENCES}

Amato, Jeffery D., 2005, "Risk Aversion and Risk Premia in the CDS Market," BIS Quarterly Review, (December), pp. 55-68. http://www.bis.org/publ/qtrpdf/r_qt0512e.htm

Bank for International Settlements, 2009, "OTC Derivatives Market Activity in the Second Half of 2008," Technical Report, BIS Monetary and Economic Department, Basel, (May). http://www.bis.org/press/p090519.htm

Due, Darrell, and Haoxiang Zhu, 2009, "Do Central Clearing Counterparties Reduce Counterparty Risk?” Stanford University, Graduate School of Business, Working Paper, (March).

Gorton, Gary, 2009, "Slapped in the Face by the Invisible Hand: Banking and the Panic of 2007," Technical Report, Yale University (April).

Hordahl, Peter, and Michael R. King, 2008 “Developments in Repo Markets During the Financial Turmoil," BIS Quarterly Review, pp. 37-52.

Moody's, 2008, “Credit Default Swaps: Market, Systemic, and Individual Firm Risks in Practice," March, Moody's Finance and Securities, Investor Report, Special Comment, Moody's Investor Services.

Segoviano, Miguel, and Manmohan Singh, 2008, "Counterparty Risk in the Over-theCounter Derivatives Market, unpublished, IMF Working Paper 08/258, (Washington: International Monetary Fund).

Singh, Manmohan, 2004, “A New Road to Recovery,” RISK (September).

Singh, Manmohan, and James Aitken, 2009 "Deleveraging after Lehman-Evidence from Reduced Rehypothecation,” unpublished, IMF Working Paper 09/42, (Washington: International Monetary Fund).

Singh, Manmohan, and Carolyn Spackman, 2009, “The Use (and Abuse) of CDS Spreads during Distress, (unpublished), IMF Working Paper 09/62, (Washington: International Monetary Fund).

Singh, Manmohan, and Karim Youssef, 2009, "The Price of Risk," forthcoming IMF WP

Standard and Poor's, 2009, “Central Counterparties May Have Positive Impact on the CDS Market.”

United States Treasury Department, 2009, "Resolution Authority for Systemically Significant Financial Companies Act of 2009," Technical Report, U.S. Treasury Department. 